\title{
A decade of washing out common bile duct stones with papillary balloon dilatation as a one-stage procedure during laparoscopic cholecystectomy
}

\author{
A. E. B. Sjer • D. M. Boland • P. J. J. van Rijn • \\ S. Mohamad
}

Received: 25 February 2009/Accepted: 17 September 2009/Published online: 23 February 2010

(c) The Author(s) 2010. This article is published with open access at Springerlink.com

\begin{abstract}
Background Laparoscopic cholecystectomy is the treatment of choice for the management of cholecystolithiasis. For the management of choledocholithiasis, a number of options exist. The effectiveness of washing out common bile duct stones with laparoscopic transcystic papillary balloon dilatation (LTPBD) in patients undergoing laparoscopic cholecystectomy (LC) as a one-stage procedure was evaluated.

Methods Retrospectively, the files of 63 patients treated with LTPBD in a one-stage procedure undergoing laparoscopic cholecystectomy between December 1996 and December 2006 were studied.

Results Fifty-three patients were treated successfully in a one-stage procedure, seven patients were treated in two steps with an endoscopic retrograde cholangiopancreatography (ERCP) postoperatively, and in three cases a conversion to open surgery was required. The median operation time was $128 \mathrm{~min}$, and the median hospital stay was 4 days. No patients developed postoperative pancreatitis. In one case contrast leakage from the common bile duct was detected. It was the only complication directly related to the LTPBD. There were no postoperative deaths.
\end{abstract}

\footnotetext{
A. E. B. Sjer

Department of Surgery, Diakonessenhuis, Utrecht,

The Netherlands

e-mail: aebsjer@gmail.com

D. M. Boland ( $\square)$. P. J. J. van Rijn

Department of Surgery, 't Lange Land Hospital, P.O. Box 3015,

2725, NA, Zoetermeer, The Netherlands

e-mail: D.Boland@1lz.nl

S. Mohamad

Department of Radiology, 't Lange Land Hospital, Zoetermeer, The Netherlands
}

Conclusions We consider the wash out of common bile duct stones after LTPBD in a one-stage procedure to be an easy to do and safe operation with great results. Cooperation with an intervention radiologist and application of an angioplastic dilatation dotter balloon catheter are the keys to success in this procedure. In our hospital, it is the treatment of choice for choledocholithiasis associated with cholelithiasis.

Keywords Common bile duct stones - One-stage procedure - Laparoscopic cholecystectomy .

Choledocholithiasis · Cholelithiasis .

Papillary balloon dilatation

Laparoscopic cholecystectomy (LC) is considered the treatment of choice in patients with cholecystolithiasis. There is however still some debate concerning the management of common bile duct stones associated with cholelithiasis [1]. The ideal technique should be minimally invasive, easy to perform, reliably clear all stones from the common bile duct (CBD), result in the shortest possible hospital stay, and leave the patient with an undisturbed function of the papilla of Vater. Although several reports on transcystic common bile duct exploration have been documented, it has not yet become generally accepted in treating patient with cholecystocholedocholithiasis [2-5]. Regarding the results of treating these patients, preservation of the papilla of Vater as well as the risk of postoperative pancreatitis are considered important issues. Therefore, we decided to ascertain whether washing out common bile duct stones after preliminary laparoscopic transcystic papillary balloon dilatation (LTPBD) could be a sound and yielding therapeutic method. 


\section{Materials and methods}

In our hospital, during 10 years (1996-2006), 1,503 consecutive patients underwent an elective or acute LC, respectively. All patients with choledocholithiasis were treated with LTPBD. Retrospectively, this series yielded 63 patients treated with LTPBD, including 35 women and 28 men. The mean age was 56 (range, 17-88) years. The clinical demographic details and pretreatment findings are shown in Table 1. Patient selection for peroperative cholangiogram was based on:

Table 1 Preoperative demographics

\begin{tabular}{lll}
\hline & $\mathrm{N}$ & Percentage \\
\hline Men & 28 & 44 \\
Woman & 35 & 56 \\
Age year (range) & 56 & $17-88$ \\
Pancreatitis & 9 & 12 \\
CVA $^{\mathrm{a}}$ & 1 & 1 \\
Cholangitis $_{\text {Decompensatio cordis }}$ & 1 & 1 \\
Instable AP & 1 & 1 \\
\hline
\end{tabular}

${ }^{a}$ Cerebrovascular accident/stroke

b Agina pectoris
- History of jaundice

- Bile stones and/or a dilated common bile duct on an echogram

- Elevated serum liver enzyme values

A peroperative cholangiogram showing any signs of obstruction as visible stones or no drainage of contrast fluid into the duodenum was considered an indication to perform a LTPBD. In patients with preoperative biliary pancreatitis, LTPBD was performed only after complete recovery.

\section{Operative technique}

The procedure is always performed under constant fluoroscopic control in the road mapping setting by a team of a surgeon and an intervention-radiologist. The surgeon is responsible for guiding the catheters intra-abdominal, whereas the radiologist manipulates the catheter and evaluates the cholangiogram. LC is started with dissection of the cystic duct as usual. When suspecting common bile duct stones, we perform a peroperative cholangiogram after clipping the cystic duct at the gall bladder side and opening it sideways, using the Imager ${ }^{\mathrm{TM}}$ II angiographic catheter (REF 31-401, Boston Scientific International S.A., Nanterre Cedex, France) positioned transcutaneously into the cystic duct over a flexible Radifocus ${ }^{\circledR}$ guidewire M (REF
Fig. 1 Dotter balloon catheter, notice the two black markers (dots) inside the balloon
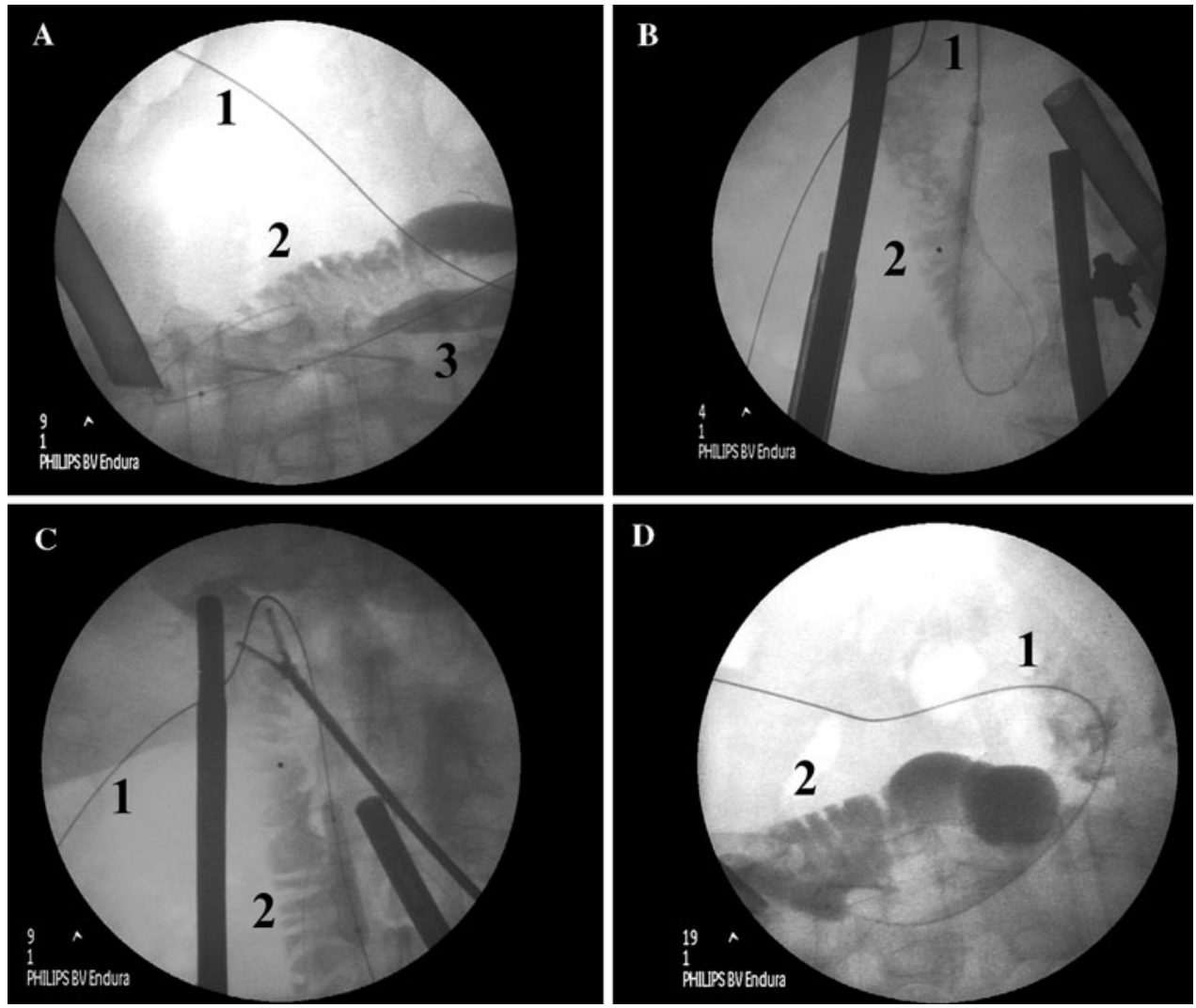
RF*GA35153M, Terumo Europe NV, Leuven, Belgium) and a contrast solution (Ultravist-300, Schering A.G., Berlin, Germany), $50 \%$ diluted with a $0.9 \%$ saline solution. In case of a stone or outflow impairment, the flexible guidewire is reinserted and, together with the angiographic catheter, advanced into the duodenum. The flexible guidewire is then replaced by an Amplatz Super Stiff ${ }^{\mathrm{TM}}$ 035/145 guidewire (REF 46-523, Boston Scientific International, La Garenne Colombes Cedex, France) followed by exchange of the angiographic catheter for a Wanda ${ }^{\mathrm{TM}}$ PTA dotter balloon catheter (REF SCH-50510, Boston Scientific International). The size of the balloon is selected between 6 to $10 \mathrm{~mm}$, in accordance with the size of the common bile duct. The next step is the first pass of the deflated balloon into the papilla of Vater (Fig. 1A). Then the balloon is inflated under fluoroscopic control using the same contrast-solution as before, so that the radiopaque markers on each side of the balloon span the sphincter (Fig. 1B). The balloon is inflated up to the point where the sphincter is dilated to the diameter of the balloon (Fig. 1C) and then deflated and repositioned into the proximal common bile duct. Reinflated in that position, the balloon prevents retrograde flow through the cystic duct during the washout. Finally, we rinse out the common bile stones into the duodenum using a $0.9 \% \mathrm{NaCl}$ saline solution. Sometimes we use the inflated balloon like the plunger in a syringe to push the stones out of the common bile duct into the duodenum (Fig. 1D). In those cases the stiff type of guidewire is extremely helpful, rigidly splinting the catheter, making it possible to push the balloon in and out the common bile duct. After clearing the common bile duct, confirmed by a final cholangiogram, we remove the balloon catheter system, close the cystic duct with conventional clips, and take out the gallbladder in the usual way.

\section{Results}

In 53 patients all the common bile stones were successfully removed in a one-stage procedure. Seven patients were

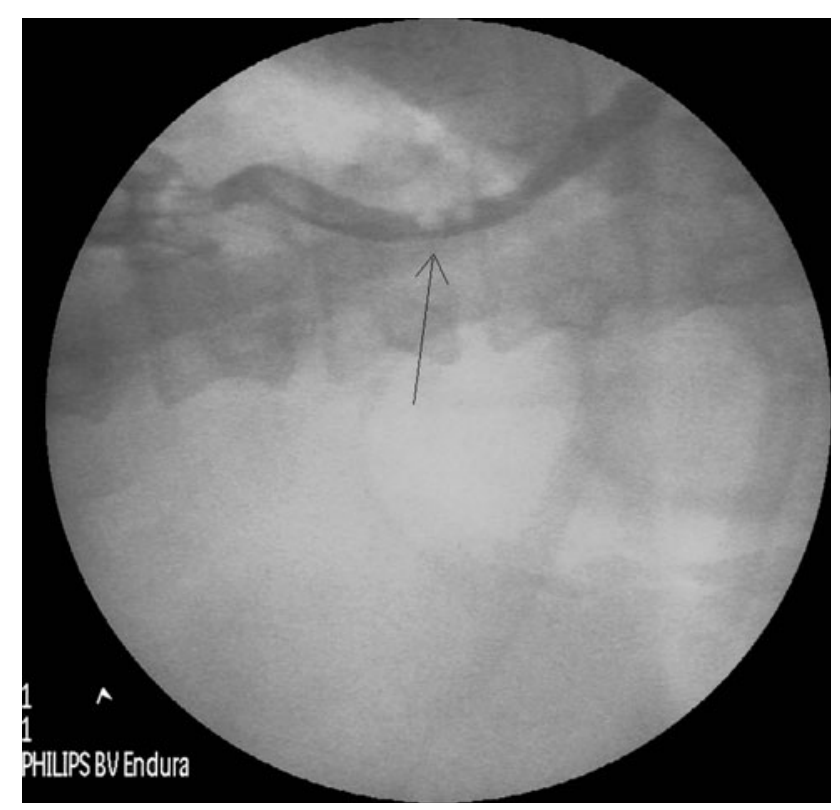

Fig. 2 Proximal part of the duodenum

subjected to an ERCP postoperatively. In three patients a conversion to open surgery was required (Table 2).

Minor postoperative complications were encountered in nine patients: incisional hernia $(\mathrm{n}=2)$, hematoma $(\mathrm{n}=2)$, postoperative bleeding $(\mathrm{n}=1)$, an intra-abdominal abscess $(\mathrm{n}=3)$, which was successfully treated by percutaneous drainage. In one patient intramural contrast leakage at the papilla of Vater occurred. The latter was the only complication directly related to the LTPBD, although it had no clinical consequences. One patient sustained an iatrogenic injury of the right hepatic duct, but this complication was not directly related to the LTPBD. Retrograde stone migration did not occur. There were no deaths involved. Retrospective analysis of the related peroperative cholangiographies resulted in an estimated mean stone size of 5 (range: 2-10) $\mathrm{mm}$ [6]. Most patients had only one stone in the common bile duct; two or more stones were rarely seen (Fig. 2). According to the learning curve (Fig. 3), the operation duration times (OR time) for performing both the

Table 2 Reasons for additional procedures and failure of LTCBDE

\begin{tabular}{lll}
\hline No. of patients & Complication & Consequence \\
\hline 1 patient & Stricture of CBD & Stent introduced into the CBD during postoperative ERCP \\
1 patient & Benign tumour near the papilla of Vater & Postoperative ERCP \\
1 patient & Multiple intrahepatic stones & Postoperative ERCP (2 residual stones removed) \\
1 patient & Rupture of the right hepatic duct & Conversion to open surgery \\
1 patient & Pinpoint stenosis of the papilla of Vater & Conversion to open surgery \\
1 patient & Multiple stones in the CBD & Conversion to open surgery \\
2 patients & Too many stones in the CBD & Postoperative ERCP (multiple residual stones removed) \\
2 patients & Persistent elevated liver function tests & Postoperative ERCP \\
\hline
\end{tabular}


Fig. 3 Distal part of the common bile duct

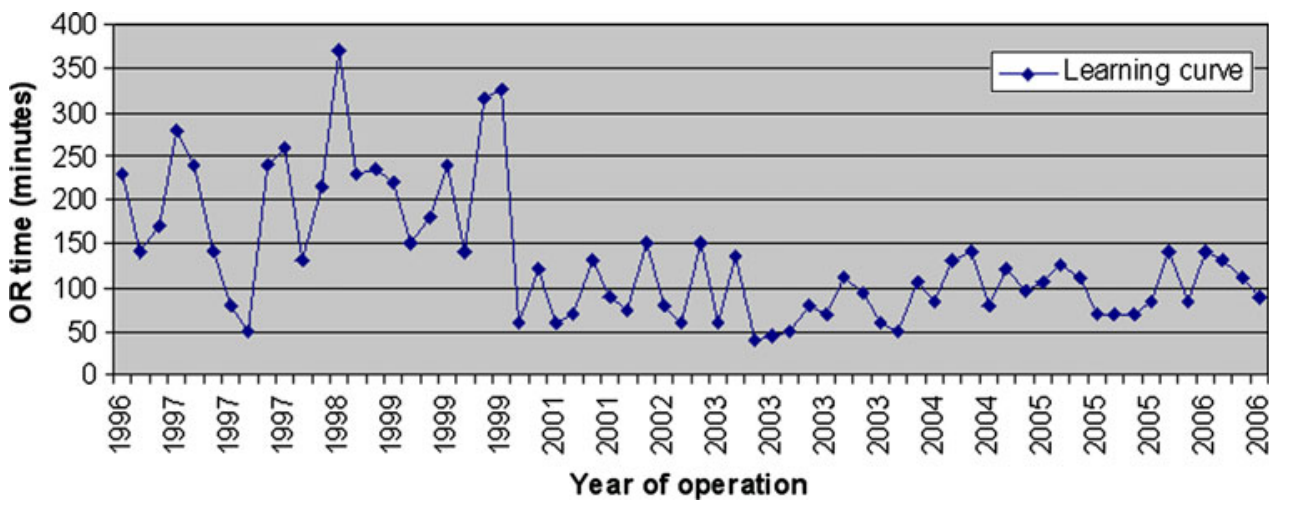

LC and the LTPBD varied from 40 to 370 min, eventually resulting in a median OR time of approximately $128 \mathrm{~min}$, including setting up all required equipment and involvement of the interventional radiologist. The median overall hospital stay was 4 (range, 2-37) days.

\section{Discussion}

In some articles the papillary balloon dilatation technique is referred to as controversial, but as far as we know there is no evidence to support this [3]. According to our study and several other articles, treatment of common bile duct stones in a one-stage procedure has the advantage over the two-stage treatment, meaning an ERCP with papillosphincterotomy followed $24-48 \mathrm{~h}$ later by LC [7-9]. For example, acute post-ERCP pancreatitis is the most serious complication, occurring after $1-30 \%$ of procedures with pancreatic necrosis in $0.3-0.6 \%$ of patients and with a related mortality of $0.4 \%[10,11]$. None of the 63 patients who we treated with LTPBD developed signs of pancreatitis. Using only downstream flow of contrast-solution instead of retrograde injection might prevent this, but our series of 63 patients was too small to be sure. Obviously, inspection of the papilla of Vater is not possible with LTPBD, but this is of minor importance. In case of a cholangiogram showing an asymmetrical papilla of Vater, a postoperative ERCP for further exploration should be performed.

We were able to manage common bile duct stones up to a diameter maximum of $10 \mathrm{~mm}$. In case of stones located in the common hepatic duct, LTPBD is not an option. To prevent rupture of the papilla of Vater, the size of the dotter balloon is chosen in accordance with the maximum diameter of the CBD. Technically, a LTPBD is fairly straightforward. In our experience it is much easier compared with laparoscopic transcystic stone extraction, using a basket catheter for example, which often is mentioned as a method for common bile duct clearance [1]. After a learning curve of approximately 25 procedures, the one-stage procedure can be performed in approximately $100 \mathrm{~min}$. There was no evidence for longer hospitalization caused directly by the LTPBD. Patients hospitalized longer than usual had severe comorbidities or they were kept hospitalized awaiting a postoperative ERCP. In our experience, only angioplastic dilatation dotter balloon catheters are suitable for performing a LTPBD. To perform a LTPBD, we advise to involve an experienced intervention radiologist who is willing to stand by while performing the one-stage procedure. In our hospital, it is the treatment of choice for choledocholithiasis associated with cholelithiasis.

\section{Conclusions}

Combined LC and LTPBD is an effective technique with great results for common bile duct clearing of stones up to $10 \mathrm{~mm}$ diameter. It is a safe and patient-friendly alternative to a two-stage approach including pre- or postoperative ERCP.

Disclosures Drs. A. Sjer, D. Boland, P. van Rijn, and S. Mohamad have no conflicts of interest or financial ties to disclose.

Open Access This article is distributed under the terms of the Creative Commons Attribution Noncommercial License which permits any noncommercial use, distribution, and reproduction in any medium, provided the original author(s) and source are credited.

\section{References}

1. Hungness ES, Soper NJ (2006) Management of common bile duct stones. J Gastrointest Surg 10(4):612-619

2. Rojas-Ortega S, Arizpe-Bravo D, Marín López ER, Cesin-Sánchez R, Roman GR, Gómez C (2003) Transcystic common bile duct exploration in the management of patients with choledocholithiasis. J Gastrointest Surg 7(4):492-496

3. Lyass S, Phillips EH (2006) Laparoscopic transcystic duct common bile duct exploration. Surg Endosc 20:S441-S445

4. Tai CK, Tang JP, Ha JPY, Chau CH, Siu WT, Li MKW (2004) Laparoscopic exploration of common bile duct in difficult choledocholithiasis. Surg Endosc 18:910-914 
5. Chikamori F, Nishio S, LeMaster JC (1999) Percutaneous papillary balloon dilatation as a therapeutic option for cholecystocholedocholithiasis in the era of laparoscopic cholecystectomy. Jpn J Surg 29:856-861

6. 't Lange Land Hospital. Cholangiographies. Available at www.llz.nl. Accessed February 2009

7. Paganini AM, Guerrieri M, Sarnari J, De Sanctis A, D'Ambrosio G, Lezoche G, Perretta S, Lezoche E (2007) Thirteen years of experience with laparoscopic transcystic common bile duct exploration for stones. Surg Endosc 21:34-40

8. Berthou JCh, Dron B, Charbonneau P, Moussalier K, Pellissier L (2007) Evaluation of laparoscopic treatment of common bile duct stones in a prospective series 505 patients: indications and results. Surg Endosc 21:1970-1974
9. Cuschieri A, Lezoche E, Morino M, Croce E, Lacy A, Toouli J, Faggioni A, Ribeiro VM, Jakimowicz J, Visa J, Hanna GB (1999) E.A.E.S. multicenter prospective randomized trial comparing two-stage vs single-stage management of patients with gallstone disease and ductal calculi. Surg Endosc 13:952-957

10. Lella F, Bagnolo F, Rebuffat C, Scalambra M, Bonassi U, Colombo E (2006) Use of the laparoscopic-endoscopic approach, the so-called "rendezvous" technique, in cholecystocholedocholithiasis. Surg Endosc 20:419-423

11. Davis WZ, Cotton PB, Arias R, Williams D, Onken JE (1997) ERCP and sphincterotomy in the context of laparoscopic cholecystectomy: academic and community practice patterns and results. Am J Gastroenterol 92:597-601 